\title{
Predictors of not always Using Seatbelts among Adults in the United States: Findings from the 2016 Behavioral Risk Factor Surveillance System
}

\author{
Gemechu B. Gerbi, MSc, PhD ${ }^{1,2 *}$, Stephanie Miles-Richardson, DVM, PhD ${ }^{1,2}$ \\ ${ }^{l}$ Department of Community Health and Preventive Medicine, Morehouse School of Medicine|720 Westview Dr. \\ SW|Atlanta, GA 30310-1495 USA \\ ${ }^{2}$ Master of Public Health Program, Morehouse School of Medicine 720 Westview Dr. SW| NCPC Suite 346| \\ Atlanta, GA 30310-1495 USA
}

\begin{abstract}
*Corresponding Author: Gemechu B. Gerbi, Department of Community Health and Preventive Medicine, Master of Public Health Program, Morehouse School of Medicine|720 Westview Dr. SW| NCPC Suite 346 | Atlanta, GA 30310-1495 USA,Email:ggerbi@msm.edu
\end{abstract}

\begin{abstract}
Objective: In the event of a crash, a seatbelt reduces the risk of injuries and fatalities among motor vehicle occupants. The objective of this study was to assess predictors of not always using a seatbelt among adults in the United States (US).

Methods: Data were analyzed from the 2016 Behavioral Risk Factor Surveillance System (BRFSS). Bivariate and multivariable logistic regression analyses were conducted to assess predictors of not always using a seatbelt among adults in the US. Analyses were conducted using SAS 9.4.

Results: After adjusting for demographic and socioeconomic factors, being male (AOR:2.10; 95\% CI, 2.002.11), being a young adult, having a low level of education and income, having been never married (AOR:1.28; 95\% CI, 1.23-1.34), being divorced (AOR:1.24; 95\% CI, 1.19-1.29), separated (AOR:1.22; 95\% CI, 1.11-1.34), widowed (AOR:1.07; 95\% CI, 1.01-1.14), residing in the Midwest (AOR: 1.80; 95\% CI, 1.741.86), Northeast (AOR: 1.26; 95\% CI, 1.21-1.31), West (AOR: 1.25; 95\% CI, 1.20-1.30) and having driven after having too much to drink (AOR: 2.12; 95\% CI, 2.00-2.24) were associated with a higher odds of reporting not always using seatbelts.

Conclusions: Findings from this study show that gender, age, racelethnicity, level of education, level of income, region of residence, and drinking and driving were predictors of not always using a seatbelt among adults in the US. This study provides data which identifies population characteristics for persons who do not always use a seatbelt. Such information allows for targeted seatbelt use interventions for populations more at risk for road traffic injuries due to lack of seatbelt use.
\end{abstract}

Keywords:Seatbelts, predictors, socio-demographic, drinking, United States

\section{INTRODUCTION}

Motor vehicle crashes are one of the leading causes of death in the United States (US) and the world [1-4]. Global data reveals that over one million deaths annually are attributable to traffic accidents, which is comparable to tuberculosis, an infectious disease, and diabetes, a chronic disease [5]. In the US, more than 33,700 people died from motor vehicle crashes in 2014 alone and more than 2.5 million people were injured and treated in emergency departments as a result of motor vehicle crashes $[4,6]$. A substantial fraction of these motor vehicle accidents were a direct results of not always using seatbelts while the vehicles were moving [7-9].
It is well-established in the literature that seatbelt use remains a highly effective method to prevent motor vehicle injuries and fatalities in motor vehicle crashes [3, 10]. Studies have shown that seatbelt use reduces the risk of death by 45 percent and the risk of moderate to critical injury in crashes by $50 \%$ [6, 10].Projections from 1975-2008, indicated that seatbelts saved approximately255,000 lives in the U.S.[11]. More than half of teens and adults who died in crashes in 2015 were not wearing seat belts at the time of the crash and 2,814 deaths could have been prevented if all passenger-vehicle occupants had been restrained using a seatbelt [6]. 
Despite the effectivities of seatbelt use in preventing death and disability among motorists involved in traffic collisions and the existing seatbelt use laws which require all occupants of a moving vehicle to be restrained[12]. Many vehicle occupants still choose not to wear their seatbelts[13] In the past, the issuance of traffic citations, or primary enforcement, was an effective deterrent [14]. A recent study, however, demonstrated that citations alone are no longer an effective deterrent [15], although there is evidence that, in some cases, motorists exhibit positive seatbelt behavior in response to a ticket [16] . Even so, factors associated with not always using seatbelt are complex and must be sufficiently explored. It is crucial to understand the characteristics of adults who do not always use a seatbelt in order to identify predictors which will allow for the development of effective intervention strategies which target populations most at risk for road traffic injuries because they are not wearing a seatbelt.

\section{MeTHODS}

\subsection{Data Source}

Data were analyzed from the 2016 Behavioral Risk Factor Surveillance System (BRFSS) to calculate predictors of not always using a seatbelt [17]. Participants' information was obtained from the 2016 BRFSS SAS data set. The BRFSS is a collaborative project between all of the 50 states in the US, the District of Columbia, three US territories (Puerto Rico, Guam, and the US Virgin Islands) and the Centers for Disease Control and Prevention (CDC). The BRFSS is designed to monitor the major health conditions, injuries, health risk behaviors, and emerging problems among noninstitutionalized adults (aged 18 years of age and older) who reside in the US and its territories [18].

The BRFSS design consists of a probability sample of all households with telephones in the state [18]. A clustering sample design was used to account for differences in the probability of selection and non-response in order to accurately derive US and state-based population estimates [19]. In 2016, more than 450,000 interviews were conducted through the BRFSS. The BRFSS survey questionnaire contains the core component asked by all states, as well as optional modules and state-added questions. The core component includes questions about demographics, perceived health conditions, and health-related behaviors. The BRFSS data are free, publicly available, and used for health policy development and advocacy at both the national and state levels[20]. A systematic review of methodological studies concluded that most self-reported health measures in the BRFSS are reliable and valid[21], and there is generally agreement between aggregate BRFSS data and data from nationally representative surveys [22].

\section{Measures}

All measures in this study were based on the self-reported data obtained from the 2016 BRFSS.

\subsection{Dependent variable (seat belt use)}

The 2016 BRFSS included a question on driver or passenger seatbelt use. One of the seatbelt use questions was: "How often do you use seatbelts when you drive or ride in a car?" There were five possible responses: always, nearly always, sometimes, seldom and never. For analyses, responses were dichotomized as "always used" versus "not always used" (i.e., "nearly always," "sometimes," "seldom," and "never") [23]. Records where the seatbelt responses were "don't know/not sure," "never drive or ride in a car," or "refused" were excluded from the analysis.

\subsection{Covariates and Independent Variables}

Socio demographic variables examined in this analysis included gender, race or ethnicity, age, education, income, marital status, and region of residence and having driven after having too much (alcohol) to drink. The prevalence of selfreported having driven after having too much to drink was defined by reporting any number above zero in response to the question: "During the past 30 days, how many times have you driven when you've had perhaps too much to drink? The response options were "_ number of days," "none," "doesn't know/not sure," or "refused." Only those records with "the number of days" and "none" were included in the analysis.

\subsection{Statistical Analyses}

We performed a bivariate analysis for an initial assessment of factors independently associated with seatbelt use. We included all variables that had achieved $\mathrm{p} \leq 0.05$ in the bivariate analysis in our final multivariable logistic regression model, and obtained the Adjusted Odds Ratios (AORs) and 95\% Confidence Intervals (95\% CIs) to estimate the magnitude of the significant associations between not always using seatbelt and independent predictors at $p \leq 0.05$. All 
Predictors of not always Using Seatbelts among Adults in the United States: Findings from the 2016 Behavioral Risk Factor Surveillance System

analyses were conducted by using SAS version 9.4 [24].

\section{RESUltS}

There were 458, 291 responses to the question "How often do you use seatbelts when you drive or ride in a car?" The majority, 397,899 (87 \%), reported always using a seatbelt while $60,399(13 \%)$ reported not always using a seatbelt (Table 1). The majority of respondents who reported they did not always use a seatbelt when they drove or rode in a car were male

Table1.Number* and percentage for self-reported who reported having used a seatbelt use by select characteristics: 2016 BRFSS, US (N=458298)

\begin{tabular}{|c|c|c|c|c|}
\hline \multirow{3}{*}{ Select Characteristics } & \multicolumn{4}{|c|}{ Seatbelt use } \\
\hline & Total & $\begin{array}{c}\text { Always used a } \\
\text { seat belt }\end{array}$ & $\begin{array}{l}\text { Did not always } \\
\text { use a seat belt }\end{array}$ & $p$-value \\
\hline & $\mathrm{n}(\mathrm{col} \%)$ & n (row \%) & n (row \%) & \\
\hline Overall & $458298(100)$ & $397899(87)$ & $60399(13)$ & \\
\hline Gender & & & & $<.0001$ \\
\hline Female & $260408(57)$ & $235187(90)$ & $25221(10)$ & \\
\hline Male & $197890(43)$ & $162712(82)$ & $38234(18)$ & \\
\hline Race/Ethnicity & & & & $<.0001$ \\
\hline White, Non-Hispanic & $350089(78)$ & $302595(86)$ & 47494 (14) & \\
\hline Black, Non-Hispanic & $36224(8)$ & $31743(88)$ & $4481(12)$ & \\
\hline Hispanic or Latino & $19450(4)$ & $17054(88)$ & $2396(12)$ & \\
\hline Multiracial & $8945(2)$ & $7671(86)$ & $1274(14)$ & \\
\hline Other & $36077(8)$ & $32381(90)$ & $3696(10)$ & \\
\hline Age Group & & & & $<.0001$ \\
\hline $18-24$ & $24742(5)$ & $19319(78)$ & $5423(22)$ & \\
\hline $25-34$ & $45239(10)$ & $36917(82)$ & $8322(18)$ & \\
\hline $35-44$ & $51523(11)$ & $44147(86)$ & $7376(14)$ & \\
\hline $45-54$ & $72355(16)$ & $63062(87)$ & $9293(13)$ & \\
\hline $55-64$ & $101423(22)$ & $89122(88)$ & $12301(12)$ & \\
\hline 65 and above & $163063(36)$ & $145370(89)$ & $17693(11)$ & \\
\hline Level of Education & & & & $<.0001$ \\
\hline Did not graduate High School & $34741(8)$ & $29327(84)$ & $5414(16)$ & \\
\hline Graduated High School & $127499(28)$ & $107134(84)$ & $20365(16)$ & \\
\hline $\begin{array}{l}\text { Attended College or Technical } \\
\text { School }\end{array}$ & $126351(28)$ & $108635(86)$ & $177162(14)$ & \\
\hline $\begin{array}{|lll|}\begin{array}{l}\text { Graduated from } \\
\text { Technical School }\end{array} & \text { College } & \text { or } \\
\end{array}$ & $168455(37)$ & $151713(90)$ & $16742(10)$ & \\
\hline Level of Income & & & & $<.0001$ \\
\hline Less than $\$ 15,000$ & $39349(10)$ & $33521(85)$ & $5828(15)$ & \\
\hline$\$ 15,000$ to $<\$ 25,000$ & $65085(17)$ & $55641(85)$ & $9444(15)$ & \\
\hline$\$ 25,000$ to $<\$ 35,000$ & $42118(11)$ & $35981(85)$ & $6137(15)$ & \\
\hline$\$ 35,000$ to $<\$ 50,000$ & $56100(14)$ & $47870(85)$ & $8230(15)$ & \\
\hline$\$ 50,000$ or more & $185581(48)$ & $163291(88)$ & $22290(12)$ & \\
\hline Region of Residence & & & & $<.0001$ \\
\hline South & $151246(34)$ & $134917(89)$ & $16329(11)$ & \\
\hline Midwest & 109982(24) & $90992(83)$ & $18990(17)$ & \\
\hline Northwest & $90384(20)$ & 78677 (87) & $11707(13)$ & \\
\hline West & $98340(22)$ & $85581(87)$ & $12759(13)$ & \\
\hline Drinking and Driving & & & & $<.0001$ \\
\hline $\begin{array}{l}\text { Have driven after having too } \\
\text { much (alcohol)to drink }\end{array}$ & $7647(3)$ & $5446(71)$ & $2201(29)$ & \\
\hline $\begin{array}{l}\text { Have not driven after having too } \\
\text { much (alcohol) to drink }\end{array}$ & $229267(97)$ & $199536(87)$ & $29731(13)$ & \\
\hline
\end{tabular}

Note: *Frequencies may vary due to missing values

ARC Journal of Public Health and Community Medicine

Page |31
(18\%), non- Hispanic White (24\%), aged 18-24 years $(22 \%)$, had high school or less education (16\%), had an annual household income $<\$ 50,000$ ( $15 \%$ for each income category), were separated (15\%) and resided in the Midwest region of the US (17\%). In addition, respondents who reported having driven after having too much to drink were more than twice more likely to report not always using a seatbelt compared to those who did not drive after having too much to drink (29\% vs. $13 \%)$. 
Predictors of not always Using Seatbelts among Adults in the United States: Findings from the 2016 Behavioral Risk Factor Surveillance System

Table2.Adjusted odds ratios (AOR) and 95\% confidence intervals (95\% CI) for self-reported not always using seatbelt by select characteristics: 2016 BRFSS, US

\begin{tabular}{|c|c|c|}
\hline \multirow[t]{2}{*}{ Select Characteristics } & \multicolumn{2}{|c|}{ Did not always use seatbelt } \\
\hline & AOR & $95 \% \mathrm{CI}$ \\
\hline \multicolumn{3}{|l|}{ Gender } \\
\hline Female & REF & - \\
\hline Male & 2.04 & $2.00-2.10$ \\
\hline \multicolumn{3}{|l|}{ Race/Ethnicity } \\
\hline White & REF & - \\
\hline African American & 0.94 & $0.89-1.00$ \\
\hline Hispanic or Latino & 0.80 & $0.73-0.85$ \\
\hline Multiracial & 0.92 & $0.84-1.01$ \\
\hline Other & 0.60 & $0.57-0.64$ \\
\hline \multicolumn{3}{|l|}{ Age Group } \\
\hline $18-24$ & 2.37 & $2.25-2.51$ \\
\hline $25-34$ & 2.08 & $2.00-2.17$ \\
\hline $35-44$ & 1.53 & $1.46-1.60$ \\
\hline $45-54$ & 1.33 & $1.27-1.40$ \\
\hline $55-64$ & 1.17 & $1.13-1.22$ \\
\hline 65 and above & REF & - \\
\hline \multicolumn{3}{|l|}{ Level of Education } \\
\hline Did not graduate High School & 1.91 & $1.80-2.04$ \\
\hline Graduated High School & 1.81 & $1.75-1.88$ \\
\hline Attended College or Technical School & 1.50 & $1.46-1.56$ \\
\hline Graduated from College or Technical School & REF & - \\
\hline \multicolumn{3}{|l|}{ Level of Income } \\
\hline Less than $\$ 15,000$ & 1.41 & $1.34-1.50$ \\
\hline$\$ 15,000$ to $<\$ 25,000$ & 1.30 & $1.25-1.36$ \\
\hline$\$ 25,000$ to $<\$ 35,000$ & 1.22 & $1.17-1.28$ \\
\hline$\$ 35,000$ to $<\$ 50,000$ & 1.28 & $1.23-1.33$ \\
\hline$\$ 50,000$ or more & REF & - \\
\hline \multicolumn{3}{|l|}{ Region of Residence } \\
\hline South & REF & - \\
\hline Midwest & 1.80 & $1.74-1.86$ \\
\hline Northeast & 1.26 & $1.21-1.31$ \\
\hline West & 1.25 & $1.20-1.30$ \\
\hline \multicolumn{3}{|l|}{ Drinking and Driving } \\
\hline Have driven after having too much (alcohol) to drink & 2.20 & $2.10-2.30$ \\
\hline Have not driven after having too much (alcohol) to drink & REF & - \\
\hline
\end{tabular}

Table 2 presents the results of a multivariable 65 and above when controlling for other logistic regression analysis for selected variables (gender, race or ethnicity, age, education, income, marital status, region of residence and drinking and driving) regressed on not always using a seatbelt when they drove or rode a car. After adjusting for the aforementioned variables and comparing to those who reported always using seatbelt, males were more likely to report not always using a seatbelt than females (AOR:2.04; 95\% CI, 2.00-2.10). Respondents aged 18-24 years (AOR:2.37; 95\% CI, 2.252.51), 25-34 years of age (AOR:2.00; 95\% CI, 2.00-2.17), 35-44 years of age (AOR:1.53; 95\% CI, 1.46-1.60), 45-54 years of age (AOR:1.33; 95\% CI, 1.27-1.40), 55-64 years of age (AOR: $1.17 ; 95 \%$ CI, 1.13-1.22) were more likely to report not always using seatbelt than those aged variables. Respondents who did not graduate from high school (AOR: 1.91; 95\% CI, 1.802.04), those who graduated high school (AOR: 1.81 ; 95\% CI, 1.75-1.88), and those who attended college or technical school (AOR: $1.50 ; 95 \%$ CI, 1.46-1.56) were $91 \%, 81 \%$ and $50 \%$ more likely, respectively, to report not always using seatbelt than those who were college or technical school graduates. Participants with an annual household income of less than $\$ 15000$, had higher odds of reporting not always using seatbelts (AOR: $1.41 ; 95 \% \mathrm{CI}$, 1.34-1.50). Those with an annual household income of $\$ 15000$ to $<\$ 25000$ (AOR: 1.30; 95\% CI, $1.25-1.36$ ), and $\$ 25000$ to $<\$ 35000$ (AOR: 1.22 ; 95\% CI, 1.17-1.28) and $\$ 35000$ to <\$50 000 (AOR: 1.28; 95\% CI, 1.23-1.33) had 
similarly higher odds. As compared with respondents living in the South, respondents living in the Midwest (AOR: 1.80; 95\% CI, 1.74-1.86), Northeast (AOR: 1.26; 95\% CI, 1.21-1.31), and West (AOR: 1.25; 95\% CI, 1.20-1.30) were more likely to report not always using seatbelt. Finally, having driven after drinking too much alcohol (AOR: 2.20; 95\% CI, 2.10-2.30) was associated higher odds of reporting not always using seatbelts (Table 2).

\section{DISCUSSION}

Motor vehicle seatbelts have been shown to cause significant reductions in the number and severity of injuries, and the occurrence of fatalities in the event that a road traffic accident occurs [25]. Unfortunately, people who do not always use seatbelts make up a disproportionate share of crashes, traffic violations and motor vehicle fatalities [7]. In this study, we assessed whether socio-demographic factors and drinking and driving behavior were associated with not always using seatbelt among adults in the US. Similar to the proportion (14\%) reported in the US in 2014 [26], our findings show that $13 \%$ of the 2016 BRFSS survey participants who responded to the seatbelt use question reported not always using a seatbelt. Our findings show that not always using seatbelt when driving or riding in a vehicle was significantly higher among males, young adults, those with a lower level of education, those with lower income, and those persons who were separated, divorced, widowed, and never married. Not always a seatbelt was also higher among respondents from the Midwest, Northeast, West region of the US and among those reported having driven at least once when they had too much (alcohol) to drink.

Prior studies have shown that people who are male, young, less educated, and have a lower income are more likely than their counterparts to report non-seatbelt use [27-29].Consistent with previous studies, [27, 30-32] our findings show that males were more likely than females to report that they did not always use a seatbelt. For example, The 2002 National Occupant Protection Use Survey revealed a statistically significant 7 percentage point gender differences in seatbelt use. Specifically, females were observed using belts 79 percent of the time compared with 72 percent of the time for males[30]. Similarly, a North Carolina survey of seatbelt use found that observed unbelted drivers were more likely to be male [31].Another study of primary and secondary seatbelt use laws found difference in four U.S. cities. Primary seatbelt laws are enforced when an officer pulls over a driver specifically for not wearing their seatbelt, whereas and secondary laws refer to motorists being cited for violating a seatbelt law only if stopped for another offense. In this study, [Boston (secondary), Chicago (secondary), Houston (primary), and New York (primary)] male drivers were less likely to buckle up than were female drivers, even in states with primary seatbelt use laws [32]. Our study used a national representative sample to confirm these significant findings related to gender and suggest the need for the development of gender specific seatbelt use programs.

With respect to age, previous studies have shown that young adults were more likely to report not always using seatbelt when driving or riding in a vehicle $[27,33]$. For example, "all the time" belt use was lowest among respondents aged 21 to 24 and highest among those aged 65 and older [33]. An observational survey of seatbelt use at 12 high schools in Connecticut and Massachusetts confirmed findings from earlier studies that teenagers have low seatbelt use rates relative to other age groups, even when they drive with their parents[34].

We observed a similar pattern with respect to educational attainment. Our findings indicate that, compared to college or technical school graduates, those who did not graduate from high school, those with a high school level of education, and those who attended college or technical school (but did not graduate) were more likely to report not always using seatbelt (94\%, 82\% and 50\%, respectively). Previous studies[31, 32] have also shown that college graduates were more likely to report driving belted than blue collar or service workers [31]. The study of seatbelt use laws in Boston, Chicago, Houston, and New York also confirmed, through driver interviews, that higher educational attainment is a strong correlate of higher seatbelt use [32].

Our study revealed that, regardless of individual demographic and socioeconomic characteristics, regional differences were observed in selfreported seatbelt usage. Compared with those who resided in the south region of the US, persons who resided in the Northeast, Midwest and West region of the US were more likely to report not always using a seatbelt. The most 
likely explanation may be attributed to differences in primary seatbelt laws and secondary laws. As of February 2017, seatbelt laws by state compiled by the Governors Highway Safety Association shows that the majority of the states in the Southern region (91\%) have primary seatbelt laws compared with $33 \%, 42 \%$ and $55 \%$ of states in Northeast, Midwest and West region, respectively [35]. Prior studies have also shown that seatbelt use was higher in states with primary seatbelt use laws than in states with secondary seatbelt use laws [36, 37]. In primary law states, seatbelt use rates were 80 percent and in secondary law states, seatbelt use rates were only 69 percent, a statistically significant difference[37]. Moreover, in those states that changed from a secondary to a primary seatbelt use law, seatbelt use increased (and fatalities decreased)[36]. For example, when Washington State changed from a secondary to a primary law state, observed seatbelt use rates rose from $83 \%$ in 2001 to 93 $\%$ in 2002 [38]. There may be several plausible explanations for the differences in the regions with primary seatbelt use laws than in states with secondary seatbelt use laws. For example, not using a seatbelt may be attributed to the lack of education and/or knowledge of actual risk. It is possible that some individuals may know that seatbelts can prevent injury, but they may not fully grasp or believe "how much" seatbelts prevent injuries [39]. A study showed that seatbelt use was lower among drivers who did not actually believe that a seatbelts would save their lives [39]. Another plausible explanation may be related to cultural beliefs. A study by Shin et al (1999) found that fatalism, or belief that one's fate is predetermined, greatly influenced seatbelt use [40]. This may possibly explain why some individuals choose to not wear a seatbelt.

The marked alcohol use and risky driving behavior in our study population are alarming. We found that, compared to respondents who have not driven after having too much (alcohol) to drink, respondents who drove after having too much to drink were more than twice more likely to report not always wearing seatbelt. The most plausible explanation for this finding is that drinking may be associated with decreased inhibitions and risk perception[41] and alcohol consumption gives people more courage (sometimes significantly more) to do what they would otherwise not have done[42]. Further, alcohol consumption makes people less aware or concerned about the consequences of driving without using seatbelt. The association between having driven after having too much (alcohol) to drink and not always using seatbelt suggests that, when considering the different aspects of seatbelt use, it is important to realize the impact of alcohol consumption on decision making with respect to driving. Furthermore, people should be educated to practice safe driving behaviors by not letting alcohol impair their decision-making process when they drive or ride a car. Developing targeted interventions among populations where the risk is greatest could lead to more useful, appropriately aimed interventions to increase seatbelt use.

\subsection{Study Limitations}

Despite the strengths of the current investigation, which include the data source and national representation of the sample, the findings in this report should be interpreted in light of at least three limitations. First, the BRFSS is a telephone-based survey and is administered to non-institutionalized adults. Therefore, the BRFSS excludes individuals without telephone service, those on military bases, and individuals in institutions. For this reason, generalizability to the entire US population is limited. Second, this study relied on self-reported information, which, because of social desirability bias, might result in higher reported frequency of seatbelt use than that reported in observational studies. The optimal method for assessing seatbelt use is direct observation [43], but this requirement is likely to be unfeasible on a large-scale, national level. Another limitation is that this analysis does not distinguish between work-related and personal driving. This is important because previous research has shown that the frequency of seatbelt use among commercial motor vehicle drivers is higher than among those engaging in personal driving[44].Finally, the BRFSS data did not allow us to quantify "having too much (alcohol) to drink".

\section{CONCLUSION}

In sum, the present study found that being male, having lower level of education, lower income, residing in the Midwest, Northeast, and West regions of the US and driving after having had too much alcohol to drink were associated with higher odds of reporting not always use a seatbelt. These findings highlight the need for focused efforts to increase seatbelt use among 
high-risk populations who might be more at risk for road traffic injuries because they do not always use a seatbelt.

\section{REFERENCES}

[1] Krug, E.G., G.K. Sharma, and R. Lozano, The global burden of injuries. Am J Public Health, 2000. 90(4): p. 523-6.

[2] Williams, A.F., S.A. Ferguson, and J.K. Wells, Sixteen-year-old drivers in fatal crashes, United States, 2003. Traffic Inj Prev, 2005. 6(3): p. 202-6.

[3] Task Force on Community Preventive, S., Recommendations to reduce injuries to motor vehicle occupants: increasing child safety seat use, increasing safety belt use, and reducing alcohol-impaired driving. Am J Prev Med, 2001. 21(4 Suppl): p. 16-22.

[4] Centers for Disease Control and Prevention, Web-based Injury Statistics Query and Reporting System (WISQARS) Fatal Injury Data. Available from: https://www.cdc.gov/injury/wisqars/overview/k ey_data.html. 2016.

[5] Toroyan, T., Global status report on road safety. Inj Prev, 2009. 15(4): p. 286.

[6] Centers for Disease and Control and Prevention, America's Health Rankings analysis of CDC, Behavioral Risk Factor Surveillance System, United Health Foundation, AmericasHealthRankings.org, Accessed 2018.

[7] Nabi, H., et al., Type A behavior pattern, risky driving behaviors, and serious road traffic accidents: a prospective study of the GAZEL cohort. Am J Epidemiol, 2005. 161(9): p. 86470.

[8] St Bernard, G. and W. Matthews, A contemporary analysis of road traffic crashes, fatalities and injuries in Trinidad and Tobago. Inj Control Saf Promot, 2003. 10(1-2): p. 21-7.

[9] Mutabazi, M., Trinidad motorists' understanding of safety belt issues. West Indian Med J, 2007. 56(3): p. 234-5.

[10] Centers for Disease Control and Prevention, Adult Seat Belt Use. Available at https://www. cdc.gov/ vitalsigns/seatbeltuse/. 2011.

[11] NHTSA., National Highway Traffic Safety Administration Traffic safety facts: occupant protection (2009). https://crashstats.nhtsa.dot.gov/Api/Public/Vie wPublication/811390 Accessed 09/26/2017

[12] Boakye, K.F., N. Shashi, and S. Mack, Nighttime Seatbelt Use of Front-Seat Passengers Based on Their Corresponding Drivers' Seatbelt Use. Transportation Research Board 2017.

[13] Birru, H., et al., A comparison of self-reported seat belt usage among the Appalachian and
non-Appalachian United States. Ann Epidemiol, 2016. 26(3): p. 227-30.

[14] Hulmut, S., et al., Factors Influencing Seatbelt Utilization in Louisiana and Strategies to Improve Usage Rate. Louisiana Transportation Research Center, 2017.

[15] Harper, S. and E.C. Strumpf, Primary Enforcement of Mandatory Seat Belt Laws and Motor Vehicle Crash Deaths. Am J Prev Med, 2017. 53(2): p. 176-183.

[16] Luca, D.L., Do Traffic Tickets Reduce Motor Vehicle Accidents? Evidence from a Natural Experiment. Journal of policy analysis and management, 2014.

[17] Centers for Disease Control and Prevention, BRFSS 2012 Survey Data and Documentation. Available from: http://www.cdc.gov/brfss/annual_data/annual_2 012.html.

[18] Jiang, Y., et al., Socio-demographic Variation of Adult Seatbelt Non-use in Rhode Island-Different Data Sources. R I Med J (2013), 2015. 98(5): p. 34-7.

[19] Takahashi, T.A., K.M. Johnson, and K.A. Bradley, A population-based study of HIV testing practices and perceptions in 4 U.S. states. J Gen Intern Med, 2005. 20(7): p. 61822.

[20] The National Center for Biotechnology Information, A Nationwide Framework for Surveillance of Cardiovascular and Chronic Lung Diseases. 2011: Washington (DC).

[21] Nelson, D.E., et al., Reliability and validity of measures from the Behavioral Risk Factor Surveillance System (BRFSS). Soz Praventivmed, 2001. 46 Suppl 1: p. S3-42.

[22] Nelson, D.E., et al., A comparison of national estimates from the National Health Interview Survey and the Behavioral Risk Factor Surveillance System. Am J Public Health, 2003. 93(8): p. 1335-41.

[23] Boal, W.L., J. Li, and R.L. Rodriguez-Acosta, Seat Belt Use Among Adult Workers - 21 States, 2013. MMWR Morb Mortal Wkly Rep, 2016. 65(23): p. 593-7.

[24] SAS Institute, C., North Carolina.

[25] Routley, V., et al., Pattern of seat belt wearing in Nanjing, China. Inj Prev, 2007. 13(6): p. 388-93.

[26] Pickrell, T.M., \& Choi, E.-H., Seat belt use in 2014 - Overall results. (Traffic Safety Facts Research Note. Report No. DOT HS 812 113). Washington, DC: National Highway Traffic Safety Administration. Available at wwwnrd.nhtsa.dot. gov/Pubs/812113.pdf. (2015, February).

[27] Beck, L.F., et al., Associations between sociodemographics and safety belt use in states 
with and without primary enforcement laws. Am J Public Health, 2007. 97(9): p. 1619-24.

[28] Lerner, E.B., et al., The influence of demographic factors on seatbelt use by adults injured in motor vehicle crashes. Accid Anal Prev, 2001. 33(5): p. 659-62.

[29] Braver, E.R., Race, Hispanic origin, and socioeconomic status in relation to motor vehicle occupant death rates and risk factors among adults. Accid Anal Prev, 2003. 35(3): p. 295-309.

[30] Glassbrenner, D., Safety Belt Use in 2002Demographic Characteristics. Research Note. DOT-HS-809-557. National Highway Traffic Safety Administration, U.S. Department of Transportation, March. 2003.

[31] Reinfurt, D., A. Williams, J. Wells, and E. Rogman., Characteristics of Drivers Not Using Seat Belts in a High Belt Use State. Journal of Safety Research, Vol. 27, No. 4, pp. 209-215. 1996.

[32] Wells, J., A. F. Williams, and C. M. Farmer., Seat Belt Use Among African Americans, Hispanics, and Whites. Insurance Institute for Highway Safety, Arlington, Va. 2001.

[33] Block, A.W., Motor Vehicle Occupant Safety Survey. Vol. 2, Seat Belt Report. National Highway Traffic Safety Administration, U.S. Department of Transportation, Nov. 2001.

[34] Williams, A.F., A. T. McCartt, and L. Geary., Seat Belt Use by High School Students. Injury Prevention, Vol. 9, pp. 25-28. 2001.

[35] Association., G.H.S., Seat Belt Laws by State (Updated February 2017). Available from http ://www.ghsa.org/state-laws/issues/Seat-Bel ts.

[36] Dinh-Zarr, T.B., et al., Reviews of evidence regarding interventions to increase the use of safety belts. Am J Prev Med, 2001. 21(4 Suppl): p. 48-65.

[37] Glassbrenner, D., Safety Belt and Helmet Use in 2002-Overall Results. DOT-HS-809-500. National Highway Traffic Safety Administration, U.S. Department of Transportation, Sept.

[38] Glassbrenner, D., Safety Belt Use in 2002Use Rates in States and Territories. Research Note. DOT-HS-809-587. National Highway Traffic Safety Administration, U.S. Department of Transportation, May.

[39] Milder, C.M., et al., Predictors of intrinsic motivation behind seatbelt use in a country where current use is low. Injury, 2013. 44 Suppl 4: p. S57-63.

[40] Shin, D., L. Hong, and I. Waldron, Possible causes of socioeconomic and ethnic differences in seat belt use among high school students. Accid Anal Prev, 1999. 31(5): p. 485-96.

[41] George, W.H., et al., Alcohol expectancies and sexuality: a self-fulfilling prophecy analysis of dyadic perceptions and behavior. J Stud Alcohol, 2000. 61(1): p. 168-76.

[42] Gerbi, G.B., et al., The correlation between alcohol consumption and risky sexual behaviors among people living with HIV/AIDS. J Subst Use, 2009. 14(2): p. 90-100.

[43] Eby DW, Vivoda JM, and C. J., Minnesota safety belt and motorcycle helmet use:August 2009. Minnesota Office of Traffic Safety; St. Paul: 2009.

[44] Kim, K. and E.Y. Yamashita, Attitudes of commercial motor vehicle drivers towards safety belts. Accid Anal Prev, 2007. 39(6): p. 1097-106.

Citation: Gemechu B. Gerbi, Stephanie Miles-Richardson. Predictors of not always Using Seatbelts among Adults in the United States: Findings from the 2016 Behavioral Risk Factor Surveillance System.ARC Journal of Public Health and Community Medicine.2019; 4(1):29-36. DOI: dx.doi. org/ 10.20431/2456-0596.0401004.

Copyright:(C) 2019 Authors. This is an open-access article distributed under the terms of the Creative Commons Attribution License, which permits unrestricted use, distribution, and reproduction in any medium, provided the original author and source are credited. 